\title{
A Pictorial Schema for a Comprehensive User-oriented Identification of Medical Apps
}

\author{
S. Bonacina; S. Marceglia; F. Pinciroli \\ eHealthLAB- Laboratorio di I nformatica BioMedica Sanità Digitale, DEIB- Dipartimento di Elettronica, \\ Informazionee Bioingegneria, Politecnico di Milano, Milano, I taly
}

\section{Keywords}

Media tablet apps, computers, handheld/ trends, credentialing, quality control, software/utilization

\section{Summary}

Objectives: The huge amount of released medical apps prevents medical app users from believing that medical scientific societies and other accreditation bodies as well, have the resources and the power for assigningto anymedical appaqualityscore. By the time being, any medical app user has to take the risks related to the frequentlyinsufficient accreditation of that app. Providing clear user-oriented schemas, to beadopted both when putting a medical App on the market and when an App comesto be evaluated by a cohort or single users, becomes crucial. Theaimofourresearch wastodefine a pictorial identification one-shot schema for a comprehensive user-oriented identification of medical apps.

Methods: Adopting a pictorial approach is common in software design modeling. To build up our identification schema we started from the limited number of Apps already available on a web site of app reviews (iMedicalApps.com), and we identified an appropriately large set of attributes for de-

\section{Correspondence to:}

Stefano Bonacina

eHealthLAB- Laboratorio di I nformatica BioMedicae Sanità Digitale DEIB

Dipartimento di Elettronica, Informazione e

Bioingegneria

Politecnico di Milano

Piazza Leonardo da Vinci, 32

20133 Milano

Italy

E-mail: stefano.bonacina@polimi.it

Website: www.ehealth.polimi.it scribing medical apps. We arranged the attributes in six main families. We organized themina one-shot comprehensive pictorial schema. We adopted a traffic light color code for assessing each attribute, that was sufficient to provide simple elements of alerts andalarmsregarding asingleApp. Then, we considered apps from iMedicalApps.com web site belonging to threemedical specialties: cardiology, oncology, and pharma and analyzed them according to the proposed pictorial schema.

Results: A pictorial schema having the attributes grouped in the families related to "Responsible Promoters", "Offered Services", "Searching Methods", "Applications Domains", "Envisaged Users", and "Qualifiers and Quantifiers" has been identified. Furthermore, we produced a one-shot pictorial schema for each considered app, and for each medical specialty, we produced it also in an aggregated form.

Conclusions: The one-shot pictorial schema provides a useful perception of when and whereto useaconsidered app. It fitspositively the expectations of potential but different user's profiles. It can be a first step towards a systematic assessment of apps from the userviewpoint.

Methods Inf Med 2014; 53: 208-224 doi: 10.3414/ME13-01-0093

received: August 21, 2013

accepted: J anuary 16, 2014

prepublished: April 14, 2014

\section{Introduction}

In the expected, butstill amazing, explosion of smartphones and tablets, Apps in the medical field are regarded as possible tools not only to improve patient-doctor interactions and communication, but also to provide "scalableand convenient" ways to supporthealth careservice delivery [1-5].

There is however a widely agreed perception that medical apps quality and safety is an underestimated problem that deserves careful consideration $[1,2,6-10,11]$. It is recent news that Apple started rejecting medical Appsif metadata do notcontainappropriate references and information sources [12]. In addition, App quality and associated risks for data protection and security is a trans-domain issue that goes beyond the medical domain, and it was addressed using computer science approaches grounded on the App's development paradigm [13] as well as on the assessment of malicious software included in the App [14]. The US Food and Drug Administration (FDA), following a guidance draft published in July 2011 [15], issued on September 2013 guidelines to regulate "Mobile Medical Applications" that can be considered as "medical devices" [16]. The last release of the guidance groups mobile medical Apps into three categories: 1) those that are considered as medical devices and fall within the regulation; 2 ) those that are not medical devices and fall outside the regulation; and 3) those that can be considered as medical devices and for which FDA will exercise enforcement discretion. Despite the specifications, it is clear that a large part of Apps available on markets for the main mobile operating systems (Apple iOS, Google Android, Windows Mobile, Blackberry RIM) remain 
(or may remain) outside the regulation, and many of the most risky Apps, such as uncontrolled and not expert-reviewed reference books, fall outside the regulation $[15,16]$. The idea of App regulation may also pose some problems related to additional costs and paperwork that may be not sustainable for developers [15] while the huge and still increasing number of released medical apps denies to believe that medical scientific societies, and other accreditation bodies as well, have the resources and the power enough to examine each medical App.

Apart from FDA regulation, others have proposed to approach the problem of App quality using standard reporting schemas to be compiled by the App manufacturers, applying the classical "quality auto-certification" strategy (Table 1) [17-20].

One short "observation" paper proposes a list of potential criteria for a self-certification of medical apps [21]. The list is adapted from the criteria proposed by the HON code [20] to obtain credited medical and health web sites, more than 15 years ago. However, the list presented in [21] is still tuned on the original HON code philosophy devoted to health website certification, and does not consider that Apps are mainly developed anticipating and interpreting user's requirements, and not relying on commissioned specifications, stated in a contract between the customer and the developer. The App-Synopsis $[17,18]$ provides a comprehensive description of the App imprint, rationale, expected functionality, content reliability, and data protection policies that manufacturers can provide to ensure that their apps are reliable and safe. Similarly, an even more detailed App specification is provided by Happtique [19], ",a mHealth solution provider, that recently released its "Health App Certification program" that consists of a list of 32 "standards", describing App operability, privacy, security, and content.

However, all these attempts are devoted to the manufacturer/developer side, and address content appropriateness mainly through the presence of appropriate references and, only marginally, on the appropriateness of the content for the target users. Conversely, users of medical Apps, either healthcare professionals or citizens/ patients/students, seek also advice regarding the service offered and the interfaces adopted to provide such contents/services in the specific view of the app user type. The guidelines to select mobile medical applications published by the Healthcare Information and Management Systems Society (HIMSS) by the mHIMSS App Usability Working Group are in fact focused on App Usability as preferential selection criterion for users when facing a huge number of Apps possibly answering their needs [22]. To this regard, besides the usually simplistic and unreliable user's satisfaction rates and number of downloads, medical Apps users can only rely on medical professional-reviews [23, 24] and/or other opinions found on the web.

On the clinical side, as shown in Table 1 , Apps are mainly evaluated by professional users focusing on their contents, in a specific medical domain, considering evidence-based medicine as main criterion: the compliance with guidelines, or the ability of an App to provide results comparable with those suggested by an experienced clinicians, together with the documented involvement of clinicians in the development process are being used to rate available medical Apps $[2,8-10,21,22,25-30]$. On the citizen/patient side, the "library of NHS reviewed phone apps to keep people healthy" is founded on evidence-based medicine [30].

However, the observations from the clinical side remain only either domainonly focused or user-only focused, analyzing and evaluating specific functionalities provided by the Apps to help patients/cliniciansin managing the pathologies the App is designed for.

The present situation claims for more comprehensive views, like an ID card, able to show a set of essential and usergrounded attributes of any generic medical App, not necessarily bounded to a medical specialty domain, understandable and potentially filled in by each of the possible interested parties. This would contribute to enrich the present situation for defining App quality and safety.

To this end, we 1) tested whether a structured one-shot pictorial schema, to be filled as a user-oriented ID card to highlight the risky factors of any medical app can be builtup, and 2) proposed a possible arrangement of such schema. We came to our schema by analyzing the reviews made bya team of medical professionals of more than 100 medical Appsin three wide clinical domains (cardiology, oncology, and pharma), and synthesizing the attributes evaluated by these reviews. Considering a traffic-light color code to provide the user's opinion on the specific attribute characterizing the App, we came to a pictorial schema open to be filled-in by any stakeholder of the medical process, including the final user, in a widely transparentprocess.

\section{Methods}

To build up our one-shot pictorial schema, we used the medical professional reviews of more than one hundred of medical apps, quoted into a widely recognized web site of medical app reviews (iMedicalApps.com) [23], from middle November 2012 to middle February 2013. After having defined the attribute families, from the review texts, we synthetized the attributes to be included in each family. We hence obtained the pictorial schema that was then used to represent not only the Apps already considered for the analysis, but also other Apps belonging to the same clinical domains.

More specifically, we adopted the following steps:

1. Choice of medical Apps reviewing sources;

2. Choice of medical Apps domains and App enrollment;

3. Single App analysis;

4. Definition of attribute families;

5. Valuable attributes;

6. Creation of the one-shot pictorial schema;

7. Application: examples of App evaluation through the one-shot pictorial schema.

\subsection{Choice of Medical Apps Reviewing Sources}

As we soughtfor an identification schema to represent medical Apps for users, we first looked for present sources of medical Apps reviews and evaluation. This approach to the usability evaluation is also 
Table 1 Present attempts of medical Apps quality evaluation

\begin{tabular}{|c|c|c|c|c|c|}
\hline \multirow[t]{2}{*}{$\mathbf{N}$} & \multirow{2}{*}{$\begin{array}{l}\text { Medical } \\
\text { domain }\end{array}$} & \multirow[t]{2}{*}{ Medical Apps Type } & \multicolumn{2}{|l|}{ Evaluation } & \multirow{2}{*}{$\begin{array}{l}\text { Refe- } \\
\text { rence }\end{array}$} \\
\hline & & & Applied criteria & $\begin{array}{l}\text { Professional involved as } \\
\text { evaluator }\end{array}$ & \\
\hline \multicolumn{6}{|c|}{ Evaluation of Apps from the clinical viewpoint } \\
\hline 1 & $\begin{array}{l}\text { Diabetes } \\
\text { management }\end{array}$ & $\begin{array}{l}\text { Apps to support patients in self- } \\
\text { monitoring blood glucose, taking } \\
\text { diabetes medications, and calculat- } \\
\text { ing insulin dose }\end{array}$ & $\begin{array}{l}\text { Efficacy of thefunctionsprovided bytheApp } \\
\text { (score 1-5) }\end{array}$ & $\begin{array}{l}\text { Researchers with medical back- } \\
\text { ground }\end{array}$ & [10] \\
\hline 2 & $\begin{array}{l}\text { Medication } \\
\text { adherence }\end{array}$ & $\begin{array}{l}\text { Apps to support patients in taking } \\
\text { their medications according to the } \\
\text { prescription(timeinterval-dose) }\end{array}$ & $\begin{array}{l}\text { List of desirable attributes including available } \\
\text { functions, data storage, security issues, costs, } \\
\text { guidelinescompliancescored and weighted }\end{array}$ & $\begin{array}{l}\text { Researchers with pharmaceuti- } \\
\text { cal background }\end{array}$ & [25] \\
\hline 3 & $\begin{array}{l}\text { Medical } \\
\text { information }\end{array}$ & $\begin{array}{l}\text { Appstosupportcliniciansinre- } \\
\text { source-limited settings indecision } \\
\text { making }\end{array}$ & $\begin{array}{l}\text { Comparison between Apps on smartphones } \\
\text { and PubMed4Hh for drug-related, diagnosis- } \\
\text { related, and treatment management-related } \\
\text { decision making }\end{array}$ & $\begin{array}{l}\text { Resident physicians at the Uni- } \\
\text { versity of Botswana }\end{array}$ & [26] \\
\hline 4 & Asthma & $\begin{array}{l}\text { Apps supporting patients inasthma } \\
\text { self-management through specific } \\
\text { toolsand/orinformation provision }\end{array}$ & Compliance with available guidelines & $\begin{array}{l}\text { Researchers with eHealth back- } \\
\text { ground }\end{array}$ & [2] \\
\hline 5 & Microbiology & $\begin{array}{l}\text { Reference microbiology Apps (guide- } \\
\text { lines, textbooks, testinterpretations); } \\
\text { antibiotic guidance (calculators, ad- } \\
\text { vices); otherAppsfor Microbiology }\end{array}$ & $\begin{array}{l}\text { Medical professional involvement in App de- } \\
\text { velopment process and evidence-based con- } \\
\text { tent }\end{array}$ & $\begin{array}{l}\text { Researchers with medical back- } \\
\text { ground }\end{array}$ & [9] \\
\hline 6 & Pain & $\begin{array}{l}\text { Apps focusing on pain education } \\
\text { and/or management targeted not } \\
\text { only to healthcare professionals but } \\
\text { also to patients }\end{array}$ & $\begin{array}{l}\text { Application purpose, functions available, } \\
\text { healthcare professionals involvement during } \\
\text { development }\end{array}$ & Pain researchers & [8] \\
\hline 7 & Dermatology & Apps for melanoma detection & $\begin{array}{l}\text { Apps Specificity, sensitivity, Positive and } \\
\text { Negative Predictive Values (PPV and NPV) } \\
\text { tested against board-certified dermatopath- } \\
\text { ologists }\end{array}$ & Dermatopathologists & [27] \\
\hline 8 & $\begin{array}{l}\text { Orthopaedic } \\
\text { surgery }\end{array}$ & $\begin{array}{l}\text { Apps to support orthopaedic sur- } \\
\text { geons }\end{array}$ & Number of reviews, popularity & Orthopaedic surgeon & {$[28]$} \\
\hline 9 & $\begin{array}{l}\text { Gross anat- } \\
\text { omy edu- } \\
\text { cation }\end{array}$ & $\begin{array}{l}\text { Appsfortertiaryeducationingross } \\
\text { anatomy }\end{array}$ & $\begin{array}{l}\text { Usability, specification, academic level, } \\
\text { quality of images and of software }\end{array}$ & $\begin{array}{l}\text { Researchers with anatomy } \\
\text { background }\end{array}$ & [29] \\
\hline \multicolumn{6}{|c|}{ Evaluation of Apps from the Manufacturer viewpoint } \\
\hline 10 & Medicine & All Medical Apps & $\begin{array}{l}\text { Criteria adapted fromtheHONCodefor the } \\
\text { development of websites with medical con- } \\
\text { tent }\end{array}$ & $\begin{array}{l}\text { Researcher with eHealth back- } \\
\text { ground }\end{array}$ & {$[21]$} \\
\hline 11 & Medicine & All Medical Apps & $\begin{array}{l}\text { Usability, Efficiency, Effectiveness, and User } \\
\text { Satisfaction }\end{array}$ & $\begin{array}{l}\text { Developed by mHIMMS (mo- } \\
\text { bile Healthacare I nformation } \\
\text { and Management System So- } \\
\text { ciety) and usable by Final users }\end{array}$ & [22] \\
\hline 12 & Medicine & $\begin{array}{l}\text { MedicalAppsthatareconsideredas } \\
\text { "Medical Devices" }\end{array}$ & Quality criteria of Medical Devices & $\begin{array}{l}\text { US Food and Drug Adminis- } \\
\text { tration }\end{array}$ & [16] \\
\hline 13 & Medicine & All Medical Apps & $\begin{array}{l}\text { Imprint, Rationale, Functionality, Validity and } \\
\text { Reliability, Data Requisitioning \&Manage- } \\
\text { ment }\end{array}$ & $\begin{array}{l}\text { Researchers with eHealth back- } \\
\text { ground }\end{array}$ & \\
\hline 14 & Medicine & All Medical Apps & $\begin{array}{l}\text { Operability standards, Privacy standards, } \\
\text { Security standards, Content standards }\end{array}$ & $\begin{array}{l}\text { Mobilehealthserviceandsys- } \\
\text { tem provider }\end{array}$ & [19] \\
\hline
\end{tabular}


suggested by HIMSS [22]: among the hints provided by HIMSS to evaluate usability, the use of review sources alternative to market reviews is encouraged to obtain an unbiased and informing advice about the App.App markets, available for all the mobile operating systems, provide some information regarding App downloads and general user satisfaction, not specifying both the type of user and the kind of "satisfaction" measured. Moreover, on the Internet, it is possible to find anecdotal reviews and comments about single Apps, as well as comparisons between Apps providing similar services. Conversely, we decided to use reviews coming from the iMedicalApps.com website [23], in which medical professional users provide their textual and blog-style feedback on Apps in several medical domains. iMedical Apps reviewers are required to be medical professionals, and to have knowledge on mobile platforms (iOS, Android). In this way, we could base our work on the opinions that medical professionals provided regarding a medical App, after they have used and tested it. In order to complete the scenario, we added to these reviews some of the information on App markets that is normally taken into consideration by users to evaluate the App (mainly the number of downloads, and the metadata regarding the developer). Since iMedicalApps does not have a commercial approach in the App selection process, nor it allows monetary funding or advertisement in exchange of App reviews (see footnotes in the iMedicalApps.com homepage), we could exclude possible biases in the Apps repository we used for enrollment.

\subsection{Choice of Medical Apps Domains and App Enrollment}

Since our work pioneers the idea to create an identification schema for medical Apps mainly based on user-oriented and usabil- ity criteria, we decided to focus on medical Apps belonging to some specific medical domains. In this way, we could retrieve a large number of Apps reviewed by medical professional users, thus facilitating the identification of App evaluation attributes. More specifically, we focused our attention on three major medical domains: cardiology and oncology, that refer to the most frequent causes of death, and pharma, that refers to the big issue of drug prescription, administration, monitoring, compliance, adherence, and interactions. Cardiology is a medical specialty in which biosignal recording and analysis is frequently used, and Apps used to either record or interpret heart functions are available for healthcare professionals as well as for patients (also including the use of third-party devices). In addition, the time-to-care is often short in some acute phases, and the availability of references to best practices and guidelines might be useful (e.g, heart attack and the

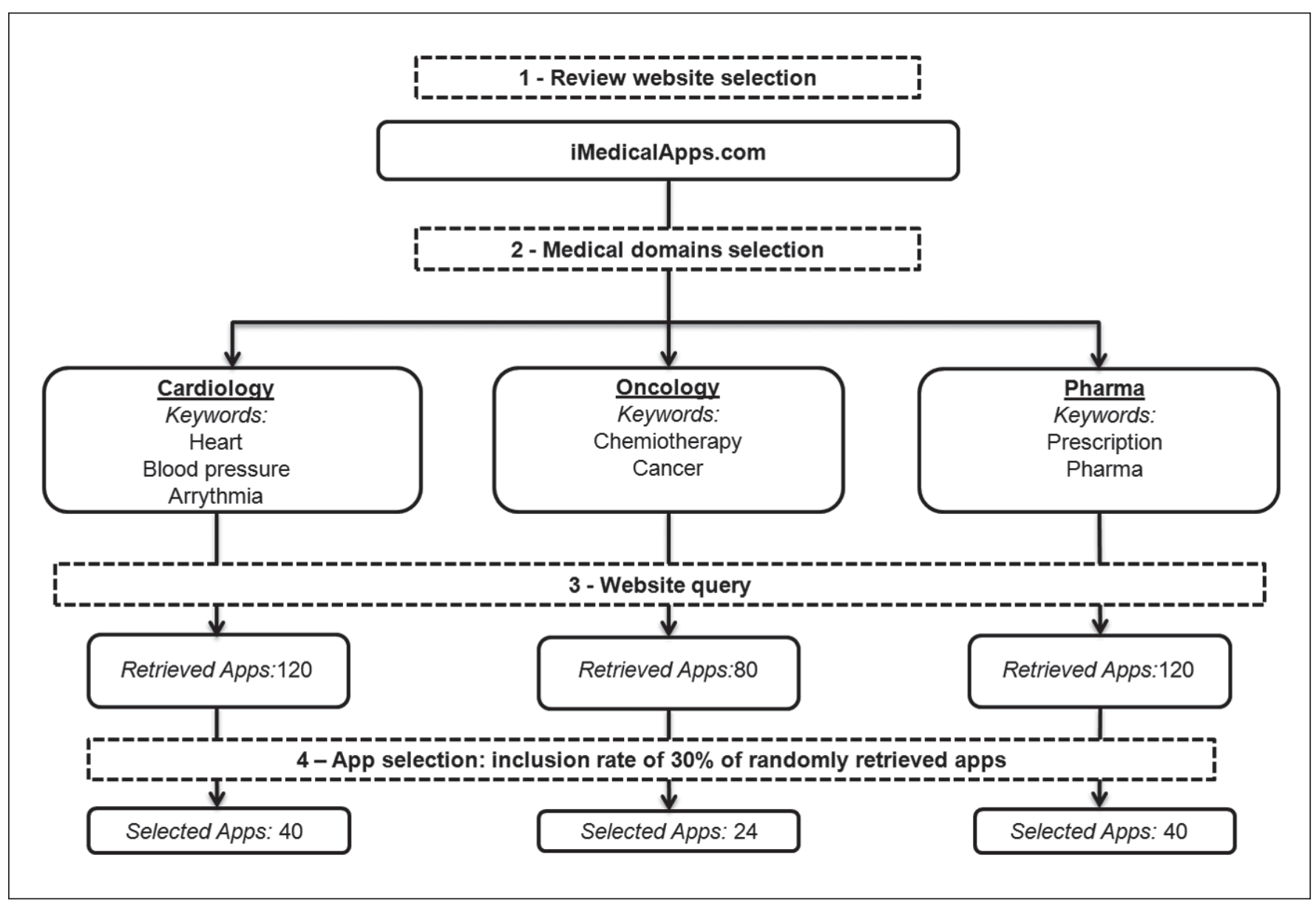

Figure 1 Flowchart of App review selection in the three clinical domains (Cardiology, Oncology, and Pharma) 
survival chain). Oncology is a medical domain in which early detection strategies are gaining increasing attention and information campaigns can be easily offered through mobile technologies. Also, the response to treatments is seen in very long time windows (usually five years), and nobody denies that patients require support from both communities and healthcare providers. All together, these three areas cover a wide range of possible heterogeneous Apps in terms of type of users, data and information treated, aims, services, andfunctions, thus likely providing agood basis for the definition of a trans-domain identification schema.

Our analysis was not aimed to rank Apps to be used in the clinical care process - as these are usually delivered within a suitably pre-designed care or educational environment - , but we pursued an objective identification of attributes that are welcome by the potential users as soon as they perceive the existence and availability of an App suitable for theirneeds.

Reviews of Apps were enrolled from the iMedicalApps [23] website, that was searched using the three main keywords "cardiology", "oncology", and "pharma", that were followed by other domain-specific terms, like "arrhythmia", "electrocardiography", "chemotherapy", to extract any remaining relevant App (Figure 1).

The search was aimed to obtain a relevant number of Apps reviewed by a team of medical professionals in the iMedicalApps website, covering the three medical domains we selected. As shown in Figure
1, we searched Apps using the domain-specific keywords, and we randomly chose the $30 \%$ of the Apps retrieved by the domainspecific search. Considering that all the Apps retrieved by the search in iMedicalApps are reviewed, after the randomization, we only excluded Apps that:

- Did not existmore on their market. This ensured that we could find App metadata and other information in the market store.

- Were available only for old operating systems. This ensured that the App could be installed, if needed.

- Were available only in a language different from English or Italian. This ensured that we were able to understand App contents, independently from the review.

\subsection{Single AppAnalysis}

Table 2 Characterization of thesingleappinitsmedical domain

\begin{tabular}{|c|c|c|}
\hline Cardiology & Drug Management & Oncology \\
\hline - App Name & - App Name & - App Name \\
\hline - Reference/Developer & - Reference/Developer & - Reference/Developer \\
\hline - Brief Description & - Brief Description & - Brief Description \\
\hline $\begin{array}{l}\text { TargetTablet(/Operating } \\
\text { System) }\end{array}$ & $\begin{array}{l}\text { TargetTablet(/Operating Sys- } \\
\text { tem) }\end{array}$ & $\begin{array}{l}\text { TargetTablet(/OperatingSys- } \\
\text { tem) }\end{array}$ \\
\hline - Price & - Price & - Price \\
\hline - Language/s & - Language/s & - Language/s \\
\hline - Year of release & - Year of release & - Year of release \\
\hline - Date of last revision & - Date of last revision & - Date of last revision \\
\hline - Envisaged Users & - Envisaged Users & - Envisaged Users \\
\hline $\begin{array}{l}\text { Medical process phase } \\
\text { (Education, Prevention, } \\
\text { Diagnosis, Therapy) }\end{array}$ & $\begin{array}{l}\text { Drug process phase(Prescrib- } \\
\text { ing, Administration, Manage- } \\
\text { ment, Therapy, Delivery) }\end{array}$ & $\begin{array}{l}\text { Medical process phase } \\
\text { (Education, Prevention, } \\
\text { Diagnosis, Therapy) }\end{array}$ \\
\hline - Validation methodology & - Validation methodology & - Validation methodology \\
\hline - Evidence-basedcontent & - Evidence-based content & - Evidence-based content \\
\hline • Privacy Management & • Privacy Management & • Privacy Management \\
\hline - Personal data acquisition & - Personal data acquisition & - Personal data acquisition \\
\hline $\begin{array}{l}\text { Positivefeatures(From } \\
\text { iMedicalApps.com) }\end{array}$ & $\begin{array}{l}\text { PositiveFeatures(FromiMedi- } \\
\text { calApps.com) }\end{array}$ & $\begin{array}{l}\text { Positive Features(From } \\
\text { iMedicalApps.com) }\end{array}$ \\
\hline $\begin{array}{l}\text { Negativefeatures(From } \\
\text { iMedicalApps.com) }\end{array}$ & $\begin{array}{l}\text { Negativefeatures(FromiMedi- } \\
\text { calApps.com) }\end{array}$ & $\begin{array}{l}\text { Negativefeatures(From } \\
\text { iMedicalApps.com) }\end{array}$ \\
\hline $\begin{array}{l}\text { Address on iMedical- } \\
\text { Apps.com Web Site }\end{array}$ & $\begin{array}{l}\text { Address on iMedicalApps.com } \\
\text { Web Site }\end{array}$ & $\begin{array}{l}\text { Address oniMedical- } \\
\text { Apps.com Web Site }\end{array}$ \\
\hline $\begin{array}{l}\text { Environment(Envisaged } \\
\text { Hospital departments or } \\
\text { Emergency Room) }\end{array}$ & & $\begin{array}{l}\text { - Images Acquisition } \\
\text { - Customization 1 (query) } \\
\text { - Customization2 (reminders) } \\
\text { - General domain } \\
\text { - Specific domain }\end{array}$ \\
\hline
\end{tabular}

From the review of each App, and also from the information available on market stores, we completed, for each App, the general descriptors listed in Table 2. They were listed according both to the criteria used in the literature (Table 1) and the authors' large experience in the eHealth domain.

The majority of them are shared among the three medical domains, and included the App name, the reference/developer, the price, the operating system, the envisaged users, the phase of the medical process (education, prevention, diagnosis, therapy) or of the drug process (assign, transmit, deliver, administer, monitor, analysis [31]) the App is used for, a brief description (aims and main functions), release and revision dates, the evaluation methodology (if any), the presence of evidence-based content, and the positive and negative aspects as evidenced by the review/s. Others are specific for the domain, as, for example, the environment (Hospital ward, Emergency, Surgery, Patient's home) for cardiology, the inclusion of images and the customizations for oncology. We did not include the App cost in the analysis, since it does not impact on App-related risks.

If any information was missing, to complete the analysis, some Apps were downloaded on tablets or smartphones available at the authors' laboratory, and other ma- 
terial such as blogs or websites in which the App was commented were taken into account.

\subsection{DefiningAttribute Families}

We defined, according to the literature [18] and relying on the elements included in the "user interface design cycle" [32] six attribute categories (that we called "families") that will be used to include the attributes of our identification schema.

1. Responsible promoters - this is the family that recalls the "imprint" criterion in the App-Synopsis. However, in our attempt, we wanted to focus on the institution/company/healthcare provider that holds the major perceived responsibility and it does not necessarily coincide with the App developer. A trusted promoter provides a positive quality element for the App. The promoter could be different from the app developer. For example, when the customer of the developeris a publisher or a drugstore, these two hold the responsibility to promote the App, even tough they did not develop the App by themselves.

2. Offered services - this family is used to identify the functions and services offeredbythe App,asindicatedin the section 5.4 of the IEC $62366: 2007$ standard [32]. From the point of view of user's evaluation, the functionalities that will be listed as attributes in this family should be those usually effective in answering the question "why does the user feel to be potentially interested into this App?".

3. Searching Methods - the attributes in this family are those describing the interfaces provided by the App to access and "consume" its contents (as in the section 5.7 of the IEC 62366:2007 standard [32]). User-friendly and clear interactive practicalities are effective in taking the user really using an app. For user's evaluation, searching methods are part of this user-App interaction, and represent "how the user wishes to use an App".

4. Application Domains - This attribute family represents the context in which the user wishes to use an app, so that the

Table 3 The rules to give each traffic light color to each family of attributes

\begin{tabular}{|c|c|c|c|}
\hline $\begin{array}{l}\text { Family of } \\
\text { attributes }\end{array}$ & GREEN & YELLOW & RED \\
\hline $\begin{array}{l}\text { Responsible } \\
\text { Promoters }\end{array}$ & $\begin{array}{l}\text { Trusted promoters well } \\
\text { known as active in the } \\
\text { field }\end{array}$ & $\begin{array}{l}\text { Something in between } \\
\text { (e.g.: promoters active } \\
\text { outof thefield of Medi- } \\
\text { cine, etc.) }\end{array}$ & Untrusted promoters \\
\hline $\begin{array}{l}\text { Offered } \\
\text { Services }\end{array}$ & $\begin{array}{l}\text { The offered services are } \\
\text { useful and appropriate } \\
\text { for the field }\end{array}$ & $\begin{array}{l}\text { Somethinginbetween } \\
\text { (e.g.: theoffered services } \\
\text { arepartiallyusefulorap- } \\
\text { propriateforthefield) }\end{array}$ & $\begin{array}{l}\text { The offered services are } \\
\text { neither useful nor appro- } \\
\text { priate for the field }\end{array}$ \\
\hline $\begin{array}{l}\text { Searching } \\
\text { Methods }\end{array}$ & $\begin{array}{l}\text { The searching methods } \\
\text { arenottrivialandthere- } \\
\text { sult-set presentation is ef- } \\
\text { fective }\end{array}$ & $\begin{array}{l}\text { Something in between } \\
\text { (e.g.: thesearching Meth- } \\
\text { odsarenotsotrivialand } \\
\text { the result-set presenta- } \\
\text { tion may make sense, } \\
\text { etc.) }\end{array}$ & $\begin{array}{l}\text { Both searching methods } \\
\text { aretrivial and result-set } \\
\text { presentation isweak }\end{array}$ \\
\hline $\begin{array}{l}\text { Application } \\
\text { Domains }\end{array}$ & $\begin{array}{l}\text { Thebordersoftheappli- } \\
\text { cation domains are fully } \\
\text { described }\end{array}$ & $\begin{array}{l}\text { Something in between } \\
\text { (e.g.: the operating do- } \\
\text { mainisonly broadlyde- } \\
\text { scribed, etc.) }\end{array}$ & $\begin{array}{l}\text { The borders of the appli- } \\
\text { cation domainsareweak } \\
\text { and mayinduce risks }\end{array}$ \\
\hline $\begin{array}{l}\text { Envisaged } \\
\text { Users }\end{array}$ & $\begin{array}{l}\text { The envisaged users are } \\
\text { clearly mentioned and } \\
\text { user needs are profiled }\end{array}$ & $\begin{array}{l}\text { Something in between } \\
\text { (e.g.: envisaged users' } \\
\text { needs are identified just } \\
\text { broadly) }\end{array}$ & $\begin{array}{l}\text { The envisaged users are } \\
\text { neither mentioned nor } \\
\text { their needs are profiled }\end{array}$ \\
\hline $\begin{array}{l}\text { Qualifiers \& } \\
\text { Quantifiers }\end{array}$ & $\begin{array}{l}\text { Availability of trusted } \\
\text { positive evaluations }\end{array}$ & $\begin{array}{l}\text { Something in between } \\
\text { (e.g.: evaluations are avail- } \\
\text { ablebutitis difficultto say } \\
\text { theyare significant) }\end{array}$ & $\begin{array}{l}\text { Availability of trusted } \\
\text { negative evaluations }\end{array}$ \\
\hline
\end{tabular}

future user can understand whether or not App contents are tuned for the specific context (see for example Standard C10.01 of the Happtique certification program or section 5.1 of the IEC 62366:2007 standard [32]). This implies that each domain-tailored app is not granted to be useful in another, even still, medical domain. Hence, Apps in which the application domain is not well defined could become risky if used in a different application domain.

5. Envisaged users - Envisaged users are those user profiles for which an App can be of potential interest. The value of this attribute resides on the effectiveness of an App for the declared user types.

6. Qualifiers \&Quantifiers - In this family, we decided to include all the objective quantifiers (i.e, number of downloads) and the subjective qualifiers (for example, user satisfaction index) that the average user welcomes to know when selecting an App. Even though these Qualifiers \& Quantifiers can be influenced by marketing issues, their relevance on user's decision making is not negligible, and they should be included in theschema.

\subsection{Valuable Attributes}

We used App reviews to identify the type of 1) responsible promoters, 2) offered services, 3) searching methods, 4) application domains, 5) envisaged users, and 6) qualifiers and quantifiers that characterized all the Apps analyzed. The values obtained for each App were categorized to identify the attributes belonging to each family. For example, if we found Apps for which the responsible promoters were hospitals, "Hospital" could become one of the attributes of the "Responsible Promoter" family. The labels to the attributes were defined by generalization: if the value of the attribute that we found in an App review fitted with any of the previous identified 
Table 4 The list of the apps considered into the assessment grouped by medical specialty

\begin{tabular}{|c|c|c|c|}
\hline$\#$ & Cardiology & Drug Management & Oncology \\
\hline 1 & - 12-Lead ECGchallenge & $\begin{array}{l}\text { AHRQePSS-TheAgencyforHealthcareResearch } \\
\text { and Quality's electronic Preventive Services Selector }\end{array}$ & - BRCAmanager App \\
\hline 2 & - AF Guide: theAtrial Fibrillation Reference & - American Medical Association My Medications & - Breast Cancer \\
\hline 3 & - AFib Educator2.0 & - Analgesic & - Breast CancerGlossary \\
\hline 4 & - Anatomy heart instant & - Antibiotics I-Pocketcards & - Cancer Coach \\
\hline 5 & - Arrhythmias & - Antibiotics Manual Flash Cards & - CancerManagement HandBook \\
\hline 6 & - Auscultation Primer & - Are My Meds Safe for my Baby? & - CancerSignsandSymptoms \\
\hline 7 & - Blood PressureDiary & - CAP guideline & - Cancer.net \\
\hline 8 & - Blood PressureReport & - Clinical PharmacologyMobile & - CancerTrialsApp \\
\hline 9 & - CalorieCounter \&DietTracker & - ClotRX & - Colorectal Cancer Miniatlas \\
\hline 10 & - Cardiac Images & - Davis Mobile Pharm Phlash! & - DoctorMole \\
\hline 11 & - Cardiograph & - Dragon Medical Search & - eCancer \\
\hline 12 & - CathSource & - Drug Doses & - i Doc 24 \\
\hline 13 & - ClotRxApp & - Drug Guide for Consumers & - Keep ABreast \\
\hline 14 & - CPR game & - Drugs andBugs & - Lange'sHistologyFlashcards \\
\hline 15 & - ECG guide & - EMRA Antibiotic Guide & - Melapp \\
\hline 16 & - ECGInterpreter, Calipers, TreatmentAdvisor & - eOpioid ${ }^{\mathrm{TM}}$ : Opioids \& Opiates Calculator & - My Self Checker \\
\hline 17 & - ECG Notes & - Epocrates & - NCCN Guidelines \\
\hline 18 & - ECG Rhythmtutor & - FIRSTlight HD & - Oncorx-mi \\
\hline 19 & - Echocardiography Atlas & - Foodand DrugAdministrationDrugSafety Podcast & - PFT a-Pocketcards \\
\hline 20 & - Heart FailureTrials & - Harriet LaneHandbook & $\begin{array}{l}\text { Pocket guide to hematologic } \\
\text { cancer }\end{array}$ \\
\hline 21 & - Heart IllustratedPro & - HAS-BLED Bleeding Risk Calculator & - Radiation Passoport \\
\hline 22 & - Heart MurmurPro & - I.V. Drug Handbook & - Re-mission \\
\hline 23 & - HeartWise Blood Pressure Tracker & - Infantrisck center & - Tumorpedia \\
\hline 24 & - History\&Physical Exami-pocketcards & - inPractice ${ }^{\circledR} \mathrm{HIV}$ & - UMSkin Check \\
\hline 25 & - iBP BloodPressure & - iPrescribe & \\
\hline 26 & - iBP Blood Pressure & - Johns Hopkins Guides & \\
\hline 27 & - iCath & - J ohns Hopkins Guides (ABX, HIV, Diabetes) & \\
\hline 28 & - iHeartTouch & - J ohns Hopkins Guides (ABX, HIV, Diabetes) & \\
\hline 29 & - Instant ECG & - Lange's Top Pharmacy 300 Drug & \\
\hline 30 & - iResus & - Lexi-Complete & \\
\hline 31 & iStethoscope & - Managing Dabigatran & \\
\hline 32 & - iVCL (Virtual Cath-Lab) & - Medescape & \\
\hline 33 & - Managing Dabigatran & - Medicine Central & \\
\hline 34 & $\begin{array}{l}\text { Master Diagnostician Series: Approach to } \\
\text { Anemia in theAdult Patient }\end{array}$ & NICE BNF & \\
\hline 35 & - Nice Guidance & - OncoRX-Ml & \\
\hline 36 & - OAPN Coronarystenting & - Oral Contraceptive Pill Reference & \\
\hline 37 & - Pocket HeartApp & $\begin{array}{l}\text { - palmEM: Emergency Medicine Essentials Quick Refer- } \\
\text { ence Guide }\end{array}$ & \\
\hline 38 & - Quit Forever & - pedi quickcal & \\
\hline 39 & - Resuscitation! & - Pediatric EmergencyDrugs & \\
\hline 40 & - SimMon & - PediDoser & \\
\hline
\end{tabular}


labels, the App was labeled accordingly. Otherwise, a new label was created.

Then, we sought for information, available in the App review, regarding the evaluation of each attribute. For example, if the responsible promoter is a publisher, the trustworthiness of the publisher resides in its activity and reputation in the field. And this information is usually evidenced in the App review, or it is easily retrievable on the Internet.

\subsection{Creation of the One-shot Pictorial Schema}

The adoption of a pictorial approach is frequently effective in software design modeling. We hence created a pictorial schema that could graphically and instantaneously synthetize ("one-shot") the values of the attributes characterizing the singleApp.

In our pictorial schema, each of the attributes has a name and has a circular shapelollipop, orstick, tobefilledin with a qualitative score, that we decided to express by the green, yellow and red traffic light colors. The rules for defining and regulating the use of each color for each family of attributes are reported in Table 3. Whereas the red color and the green color are well defined, the yellow is "something in between". Even though this evaluation scale does not precisely rank the "score" of an App, the three-scale code is enough to evi-

Table 5 Family and attribute description, and the number of occurrences of each attribute in the selected App reviews. Note that, in some cases, the number of occurrences of attributes in afamily is higherthanthetotal number ofApps selected. Thisisduetothepossibilitythat anApp satisfies morethanoneattribute (for example: an App can offer both guidelines and newsletters).

\begin{tabular}{|c|c|c|c|c|c|c|}
\hline \multirow{2}{*}{$\begin{array}{l}\text { Family } \\
\text { description }\end{array}$} & \multicolumn{2}{|c|}{ Attribute Description } & \multicolumn{4}{|c|}{ Number of occurrencesin App reviews } \\
\hline & Name & Rationale & $\begin{array}{l}\text { Cardio- } \\
\text { logy }\end{array}$ & $\begin{array}{l}\text { Onco- } \\
\text { logy }\end{array}$ & Pharma & Total \\
\hline \multirow{8}{*}{$\begin{array}{l}\text { Responsible } \\
\text { Promoters: } \\
\text { institution/com- } \\
\text { pany/health- } \\
\text { care provider } \\
\text { that holds the } \\
\text { major perceiv- } \\
\text { ed responsibil- } \\
\text { ity. The pro- } \\
\text { moter could be } \\
\text { different from } \\
\text { the app devel- } \\
\text { oper }\end{array}$} & $\begin{array}{l}\text { Medical System } \\
\text { Companies }\end{array}$ & $\begin{array}{l}\text { Possibleresponsiblepromotersasanappcanhel ppatientstomanage } \\
\text { personalized devices. }\end{array}$ & 27 & 1 & 0 & 28 \\
\hline & $\begin{array}{l}\text { Drug } \\
\text { companies }\end{array}$ & $\begin{array}{l}\text { Possible responsible promoters as an app can help prescribers to } \\
\text { manage personalized drugs. }\end{array}$ & 1 & 0 & 0 & 1 \\
\hline & $\begin{array}{l}\text { National } \\
\text { Services }\end{array}$ & $\begin{array}{l}\text { Possibleresponsiblepromoters becausetheyareincharge of the } \\
\text { responsibility tohelpinprotectingthepopulation: apps can benew } \\
\text { tools for prevention and instruction. }\end{array}$ & 1 & 0 & 6 & 7 \\
\hline & Hospitals & $\begin{array}{l}\text { Publicand privatehospitalscanappreciatetheappmodalityfordeliver- } \\
\text { ing-on-demandindications, withoutexcluding acertain degreeoftheir } \\
\text { interest in patient loyalty, too. }\end{array}$ & 1 & 0 & 11 & 12 \\
\hline & Drugstores & $\begin{array}{l}\text { Possible responsible promoters in order to serve better its customers, } \\
\text { for example by providing them with an app to caremoreabout the } \\
\text { correct assumption of the drugs on sale. }\end{array}$ & 0 & 0 & 1 & 1 \\
\hline & $\begin{array}{l}\text { Medical } \\
\text { Association }\end{array}$ & $\begin{array}{l}\text { Possible responsible promoters as an app can make the access to guide- } \\
\text { lines/recommendations issued available everywhere. }\end{array}$ & 2 & 10 & 2 & 14 \\
\hline & Publisher & $\begin{array}{l}\text { PossibleresponsiblepromotersasanAppcanfacilitatetheaccessto } \\
\text { knowledge. }\end{array}$ & 3 & 13 & 24 & 40 \\
\hline & \multicolumn{2}{|c|}{ Total Responsible Promoters } & 35 & 24 & 44 & 112 \\
\hline \multirow{9}{*}{$\begin{array}{l}\text { Offered ser- } \\
\text { vices: } \\
\text { functionalities } \\
\text { are effective in } \\
\text { answering the } \\
\text { question "why } \\
\text { the user comes } \\
\text { to this App?". }\end{array}$} & Handbooks & $\begin{array}{l}\text { Apps that make content of medical education available anywhere, } \\
\text { even at student's home }\end{array}$ & 10 & 9 & 20 & 39 \\
\hline & Guidelines & $\begin{array}{l}\text { Tools that provide the available recommendations to guarantee the } \\
\text { correct management of the patient, mainly in emergency situation in the } \\
\text { medical practice. }\end{array}$ & 15 & 2 & 27 & 44 \\
\hline & Newsletters & Information coming fromcommunities and provided totheusers. & 0 & 1 & 8 & 9 \\
\hline & Calculators & $\begin{array}{l}\text { Services that provide indicators calculated from anatomical parameters } \\
\text { (for example, Body Max Index calculator, drug dose calculator). }\end{array}$ & 5 & 5 & 17 & 27 \\
\hline & Forecasters & $\begin{array}{l}\text { Resultofsimplecalculus/algorithmsthatcanbeusedtoforecastapa- } \\
\text { tient'sstate, oracondition(for example, survival expectations). }\end{array}$ & 5 & 5 & 1 & 11 \\
\hline & Geo-Health & $\begin{array}{l}\text { Services that help in finding rapid - and even graphically mapped- } \\
\text { answers to questions like "where is the nearest pharmacy/ emergency } \\
\text { room / etc.?" }\end{array}$ & 0 & 1 & 2 & 3 \\
\hline & Simulators & $\begin{array}{l}\text { Virtual spaces where to test alternative procedures, of various type, for } \\
\text { keeping the impact on the patient as safeas possible. }\end{array}$ & 14 & 0 & 1 & 15 \\
\hline & Others & $\begin{array}{l}\text { Services for monitoring, measuring, bio-signal classifying, alert manage- } \\
\text { ment. }\end{array}$ & 0 & 5 & 2 & 7 \\
\hline & \multicolumn{2}{|c|}{ Total Offered Services } & 49 & 28 & 78 & 155 \\
\hline
\end{tabular}


Table 5 Continued.

\begin{tabular}{|c|c|c|c|c|c|c|}
\hline \multirow{2}{*}{$\begin{array}{l}\text { Family } \\
\text { description }\end{array}$} & \multicolumn{2}{|c|}{ Attribute Description } & \multicolumn{4}{|c|}{ Number of occurrencesin App reviews } \\
\hline & Name & Rationale & $\begin{array}{l}\text { Cardio- } \\
\text { logy }\end{array}$ & $\begin{array}{l}\text { Oncol- } \\
\text { ogy }\end{array}$ & Pharma & Total \\
\hline \multirow{8}{*}{$\begin{array}{l}\text { Searching } \\
\text { methods: } \\
\text { They are part of } \\
\text { this user-App } \\
\text { interaction, and } \\
\text { represent "how } \\
\text { theuser wishes } \\
\text { touseanApp". }\end{array}$} & $\begin{array}{l}\text { Alphabetical } \\
\text { Order }\end{array}$ & Searching method where items are listed in alphabetical order. & 6 & 9 & 28 & 43 \\
\hline & Images & $\begin{array}{l}\text { Searching methods managing "images" and videos including also sem- } \\
\text { antic querying. }\end{array}$ & 9 & 2 & 8 & 19 \\
\hline & $\begin{array}{l}\text { Predefined } \\
\text { Comparisons }\end{array}$ & $\begin{array}{l}\text { Thismethodletstheusercomparein asingleviewmore imagesorin- } \\
\text { formation. }\end{array}$ & 7 & 2 & 14 & 23 \\
\hline & Multisources & $\begin{array}{l}\text { Appsallowing "multisource" bioimage availability and comparisonsto } \\
\text { provide different views and insights on the same tissue (for example: CT } \\
\text { scan and MRI ). }\end{array}$ & 11 & 2 & 10 & 33 \\
\hline & $\begin{array}{l}\text { Chemical Struc- } \\
\text { tures }\end{array}$ & $\begin{array}{l}\text { Searching method that allows users to navigate inside the chemical } \\
\text { structures of drugs or human tissues. }\end{array}$ & 0 & 0 & 2 & 2 \\
\hline & $\begin{array}{l}\text { Scrolling of } \\
\text { Lists }\end{array}$ & $\begin{array}{l}\text { List of itemsthat the user can select: it is a useful tool, but, for long lists, } \\
\text { its effectiveness decreases. }\end{array}$ & 19 & 14 & 27 & 60 \\
\hline & Others & Searching methods based on keywords, videos, interactive menus. & 1 & 6 & 1 & 8 \\
\hline & \multicolumn{2}{|c|}{ Total Searching Methods } & 53 & 35 & 90 & 178 \\
\hline \multirow{8}{*}{$\begin{array}{l}\text { Application do- } \\
\text { main: } \\
\text { the context in } \\
\text { which the user } \\
\text { wishes to use } \\
\text { an app }\end{array}$} & $\begin{array}{l}\text { Complex Pre- } \\
\text { scription }\end{array}$ & $\begin{array}{l}\text { App mainly thought to support the prescription process, especially when } \\
\text { it requires multifactorial evaluationsor the combination of morethan } \\
\text { one drug/treatment. }\end{array}$ & 4 & 0 & 25 & 29 \\
\hline & Education & $\begin{array}{l}\text { Appthoughtfor theeducation of medical studentsor of otherhealth } \\
\text { professionals. }\end{array}$ & 18 & 16 & 12 & 46 \\
\hline & Mobility & $\begin{array}{l}\text { App mainlythoughtfor localization, navigation, andavailabilityofcon- } \\
\text { tents in mobility. }\end{array}$ & 2 & 7 & 17 & 26 \\
\hline & Emergency & $\begin{array}{l}\text { App mainlythoughtto supporttheinstant delivery of the besteverac- } \\
\text { quired aggregated and multidisciplinary knowledge. }\end{array}$ & 3 & 0 & 3 & 6 \\
\hline & Drug Shortage & $\begin{array}{l}\text { App mainlythoughtto supporttheimmediatesupply of drugs in order } \\
\text { to guaranteethe continuityin medical assistance for exampleinsidea } \\
\text { hospital orresthomewherea highnumber of patients aretreated with } \\
\text { drugs stored in an unique pharmacy. }\end{array}$ & 2 & 0 & 1 & 3 \\
\hline & $\begin{array}{l}\text { Specific Sub- } \\
\text { Specialty }\end{array}$ & $\begin{array}{l}\text { Specificdomaindedicatedtothe diagnosisand treatmentofspecific dis- } \\
\text { easesin a medical sub-domain (for example: breast cancer) }\end{array}$ & 25 & 13 & 0 & 38 \\
\hline & Video Manual & $\begin{array}{l}\text { Training domain based on video manuals, also for patients/citizens (for } \\
\text { example: video instructions on the use of a drug) }\end{array}$ & 6 & 3 & 0 & 9 \\
\hline & \multicolumn{2}{|c|}{ Total Application Domain } & 60 & 39 & 58 & 157 \\
\hline \multirow{5}{*}{$\begin{array}{l}\text { Envisaged } \\
\text { users: } \\
\text { thoseuserpro- } \\
\text { files for which } \\
\text { anAppisof po- } \\
\text { tential interest }\end{array}$} & Students & Students of medicine. & 23 & 4 & 7 & 34 \\
\hline & Citizens & Including patients. & 14 & 18 & 8 & 40 \\
\hline & Professionals & Health professionals. & 34 & 9 & 42 & 85 \\
\hline & Others & Caregivers, family of patient, National Services employees. & 0 & 1 & 0 & 1 \\
\hline & \multicolumn{2}{|c|}{ Total Envisaged Users } & 71 & 32 & 57 & 160 \\
\hline \multirow{5}{*}{$\begin{array}{l}\text { Qualifiers and } \\
\text { Quantifiers: } \\
\text { all the informa- } \\
\text { tion that the } \\
\text { average user } \\
\text { welcomes to } \\
\text { know when se- } \\
\text { lecting an App. }\end{array}$} & $\begin{array}{l}\text { Significant Tes- } \\
\text { timonial }\end{array}$ & LikeNational Services, Medical associations, or recognized specialists. & 0 & 5 & 24 & 29 \\
\hline & Timing & $\begin{array}{l}\text { Release date: timing attribute aggregates sub-attributes like "beginning } \\
\text { date" and "trend"(continuousintime, periodic, concentrated in ashort } \\
\text { time window) }\end{array}$ & 2 & 0 & 1 & 3 \\
\hline & $\begin{array}{l}\text { User Satisfac- } \\
\text { tion Index }\end{array}$ & $\begin{array}{l}\text { Subjective perceptions like: a positive/negative judgment on a credited } \\
\text { blog, the number of finger up/downinsocial networks, an insight pub- } \\
\text { lished ona(scientific) journal, thepersonalopinion, thestarratingavail- } \\
\text { able on App markets. }\end{array}$ & 40 & 3 & 40 & 83 \\
\hline & $\begin{array}{l}\text { Download } \\
\text { Number }\end{array}$ & $\begin{array}{l}\text { It represents how many times the App was downloaded (Usually avail- } \\
\text { able in the App market) }\end{array}$ & 0 & 1 & 9 & 10 \\
\hline & \multicolumn{2}{|c|}{ Total Qualifiers and Quantifiers } & 42 & 9 & 74 & 125 \\
\hline
\end{tabular}


dence its risks and the advantages. Hence, if an attribute could not be clearly set to green or red, it was set to yellow. Each family of attributes belongs to a rectangle, upon which attributes' lollipops are connected to.

\subsection{Application: Examples of App Evaluation through the One-shot Pictorial Schema}

Toverify whether this pictorial approach can lead to an easily perceivable and effective identification schema for medical apps, we applied it to all the Apps we have enrolled in our study, and produced more than one hundred pictorial schemas.

Furthermore, we tried to see whether the one-shot pictorial schema was able to synthetize the information regarding more Apps belonging to the same domain. To do so, we built another version of the one-shot pictorial schema in which we substituted the lollipops with bars representing the number of Apps having a green/yellow/red score in their single pictorial schema.

Finally, to verify the consistency of the attributes we have obtained, we applied the schema to other Apps retrieved from the NHS App Library [30], and saw whether they fit in the schema. An independent user (biomedical engineer, $\mathrm{PhD}$ candidate) was provided by the empty schema, the family and attribute description as in Table 5, and the color coding (Table 3 )

and was requested to randomly select three Appsin the NHS App Library, one for cardiology, one for oncology, and one for pharma and to fill in the pictorial schema for them, by either using available medical professional-reviews or by using the App on the personal mobile device.

\section{Results}

\subsection{Apps Enrollment and Analysis}

As reported in $>$ Figure 1, the search started in iMedicalApps.com resulted in about 120 Apps in the cardiology domain, 120 Apps in the pharma domain, and 80 in the oncology domain. We randomly selected the $30 \%$ of the Apps retrieved in each group, so that we enrolled 40 Apps for the cardiology domain, 24 Apps for the oncology domain, and 40 Apps for the pharma domain. Table 4 reports the names of the Apps enrolledin thestudy for each medical domain.

Considering the six families defined above, we extracted from the descriptions and reviews the categories of attributes belonging to the families, according to the results in Table 5. The final attribute set was:

1. Responsible Promoters (Publisher, Medical Association, Drugstores, Hospitals, National Services, Drug Company, Medical Systems Company)

2. Offered Services (Handbooks, Guidelines, Newsletters, Calculators, Forecasters, GeoHealth, Simulators, Others)

3. Searching Methods (Alphabetical Order, Images, Predefined comparisons, Multi-sources, Chemical structures, Scrolling of lists, Others)

4. Applications Domains (Complex prescriptions, Education, Mobility, Emergency, Drug shortage, Specific domain specialty, Video manual)

5. Envisaged Users (Students, Citizens, Professionals, others)

6. Qualifiers \& Quantifiers (Download number, User satisfaction index, Timing, Significanttestimonial).

The attribute sets we obtained are in line with the following considerations:

Responsible promoters. Publishers, aiming to diffuse knowledge, are possible responsible promoters, as an app can facilitate the access to knowledge. Also for "medical association", an app can make the access to guidelines/recommendations issued available everywhere. Even if less usual, a "drugstore" may try to serve better its customers, for example by providing them with an app to care more about the correct assumption of the drugs on sale. The "National Services", that are in charge of the responsibility to help in protecting the population, are included, too. For such services, an app can fasten the time to reach citizens with short and precise indications. Also public and private "hospitals" can appreciate the app modality for delivering-on-demand indications, without excluding a certain degree of their interest in patientloyalty, too. A "drug company", as well as "medical systems companies", can help both prescribers and patients to manage personalized and risky drugs/devices. Fora "responsible promoter", its missionin promoting an App should be easily and clearly perceived by any citizens, and associated to the promoter responsibility profile.

Even though Offered Services and functionalities usually depend on the specialty/pathology is intended for, broad categories can still be defined. For example, a "Calculator" is a useful service. An entrylevel example for the medical domain is the Body Mass Index (BMI) calculator. The usual BMI formula is widely agreed. But, if a calculus is only on the back and its results are presented as a "Forecaster" - the case can be that of survival expectations -, the scientific credentials of such forecasting actions should be declared with evidence and referenced in detail. "Newsletters" also are a useful service, as they tell what is going to be different in respect to the even recent past. "Guidelines" and "Handbooks" are well-known domains of both medical practice and medical education, and an app can make their content really available anywhere, even at student's home. "Simulators" aim to offer a virtual environment where to test alternative procedures, of various type, for keeping the impact on the patient as safe as possible, even if postponed. "Geohealth" apps help in finding rapid - and even graphically mapped - answers to questions like "where is the nearest pharmacy/ emergency room / etc.?".

Searching Methods. The value of the user-App interaction depends on its effectiveness: there is no doubt that "Scrolling a list" is a useful tool, but for long lists on small-sized displays, its effectiveness decreases. The availability of the usual wordprocessor-like searching modalities within a text is a frequently expected step forward. Moreover, given the relevance that bio-images have in the domain of medical diagnosis and therapy, searching methods managing "Images" and videos are highly appreciated in medicine, also for especially tablet PCs with their larger screen size better suited for visualization. Tools for "Pre-defined comparisons" let the user compare in a single view more images. Moreover, since different bio-images may provide different views and insights on the 
same tissue, apps allowing "Multisource" bioimageviews can be very effective.

Application Domains. A broad definition of the application domains is based on the categorization on the contexts in which the App can be used: "Education" asks for knowledge insights progressively developed from a general and gross towards a specific and complex granularity, delivered also according to the envisaged learning speed and skills of the learners. Conversely, "Emergency" conditions ask for the instant delivery of the best ever acquired aggregated and multidisciplinary knowledge. Other similarly envisaged domains are "Complex prescription", "Mobility”, "Drug shortage", "Specificsub-specialties".

Envisaged Users. The definition of attributes in the "Envisaged Users" family highlights a subgroup of major stakeholders only, as singled out by "Students", "Citizens" (including patients), and "Professionals".

Qualifiers \& Quantifiers. The "Number of downloads", even though not fully informative about quality, should not be ignored. This means that an about-never downloaded app (zombie App) will likely be poor in quality and effectiveness. The release date is also to be considered through the attribute "Timing", that aggregates sub-attributes like "Beginning date" and "Trend". We additionally diversified the latter among "Sharp", "Waved" and "Smooth", while we left "Pseudo-constant" with greater evidence. An example of "Sharp" is when everybody downloaded the app just the day after it was released, but nobody did so later on. An example of "Waved" is for seasonal allergies and related action, as well as for the major deadlines of any academic year. Wealso added the attribute "User satisfaction index", intended as a qualifier. A positive/negative judgmenton a creditedblog, thenumber of finger up/down in social networks, an insight published on a (scientific) journal, the personal opinion of users/clinicians: all these are examples of subjective perceptions to evaluate this attribute.

\subsection{The One-shotPictorial Schema}

Figure 2 shows the pictorial one-shot identification schema created using the attribute families described above. The centralemptyarea of the schema is used to include the app official name and its official description, together with the icon of the declared app operating system/s and device (iPad, iPhone, Android smartphone, Android Tablet, Blackberry, and Windows Mobile). A general evaluation of the attribute family, independentfrom the value of the singleattributes, can be provided by using the circlewithin the rectangles.

\subsection{Application of the One-shot Pictorial Schema to the Enrolled Apps}

For each of the Apps considered in our study, we produced a one-shot pictorial schema following the rules and the coding described above. We produced 40 one-shot pictorial schemas for the cardiology do-

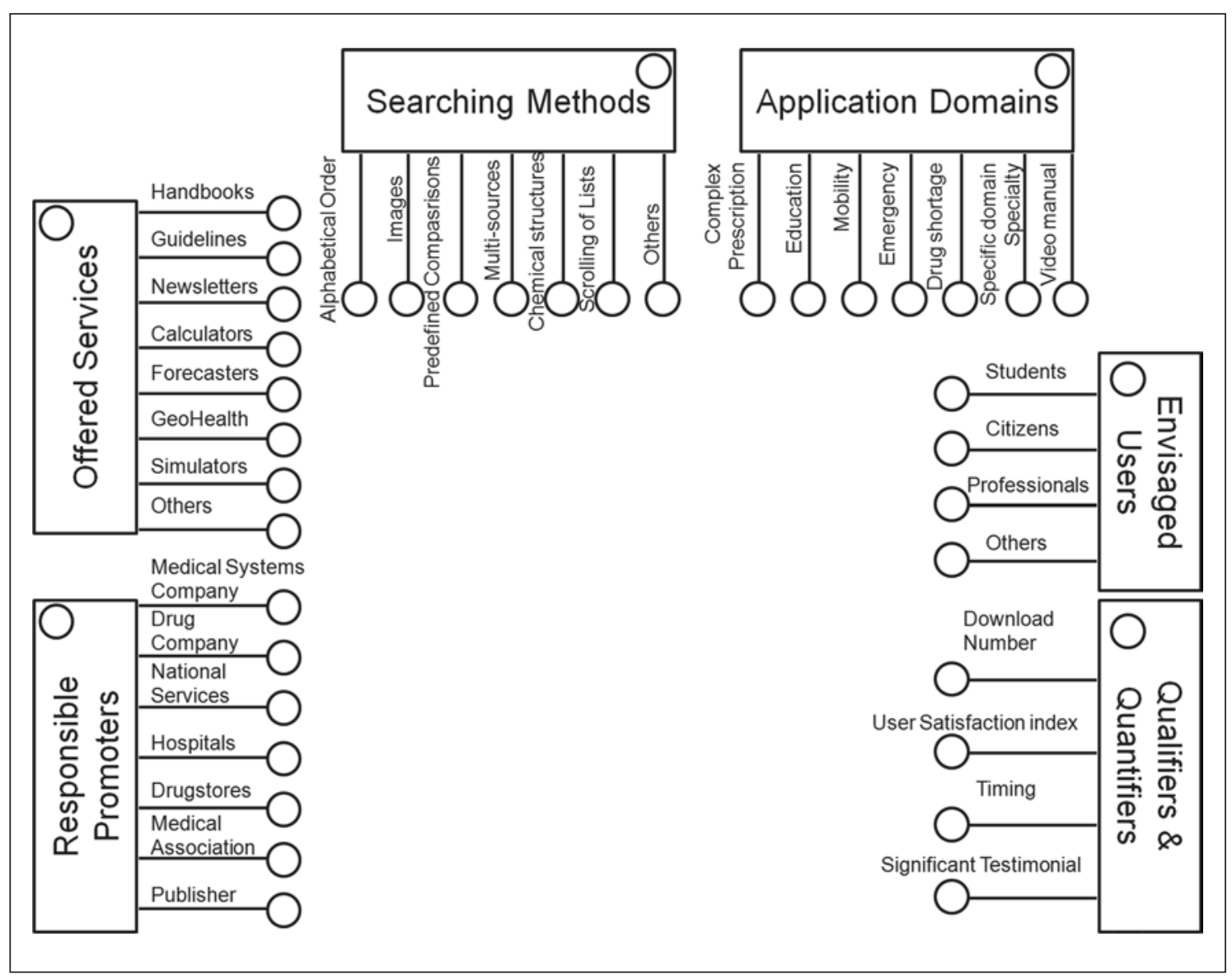

Fig. 2

The Pictorial Schema for theassessment of the Apps 
Figure 3

Assessment of the "AFGuide: theAtrial Fibrillation Reference" app

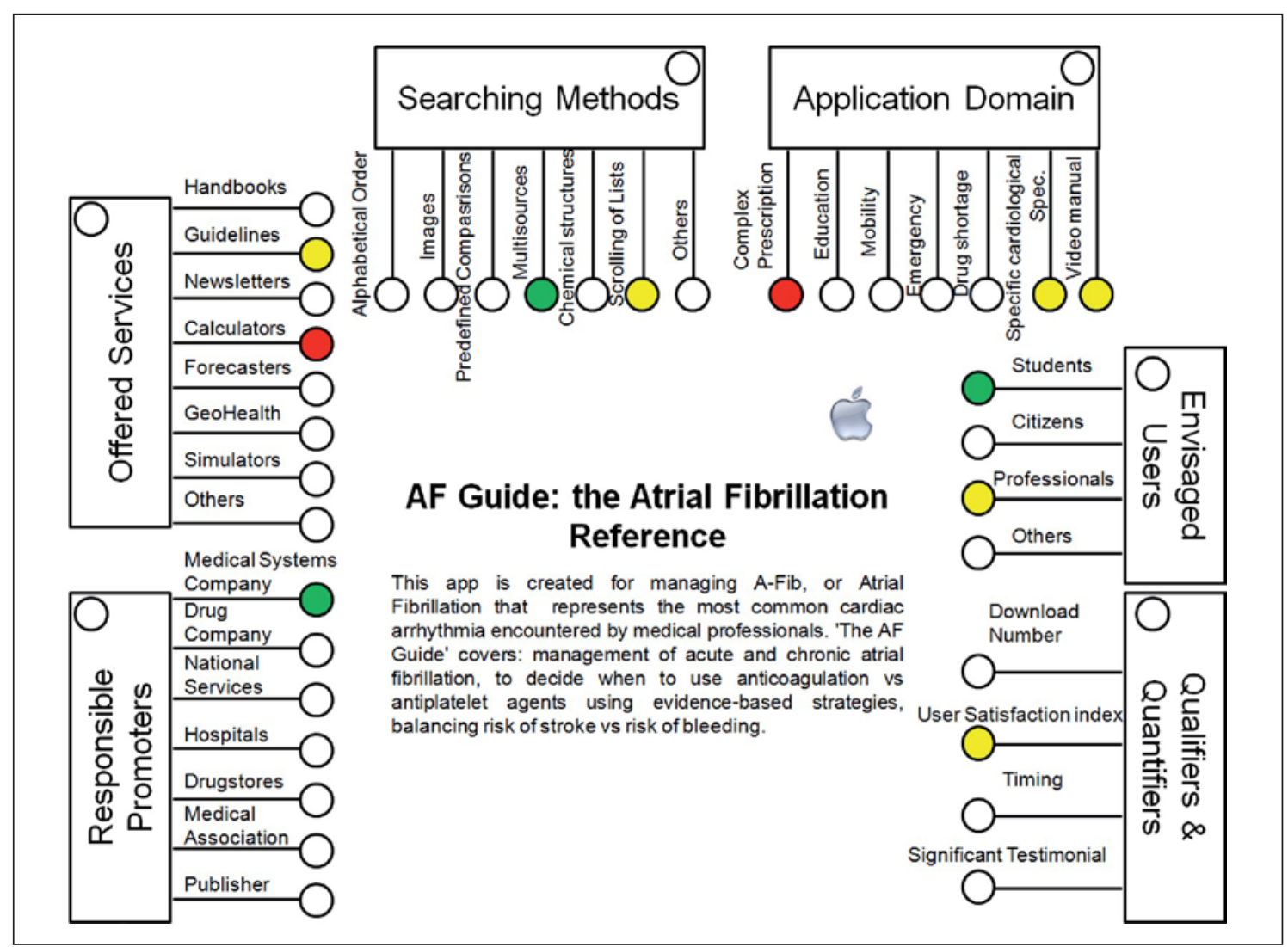

Figure 4

Assessment of the "BRCA Manager" app

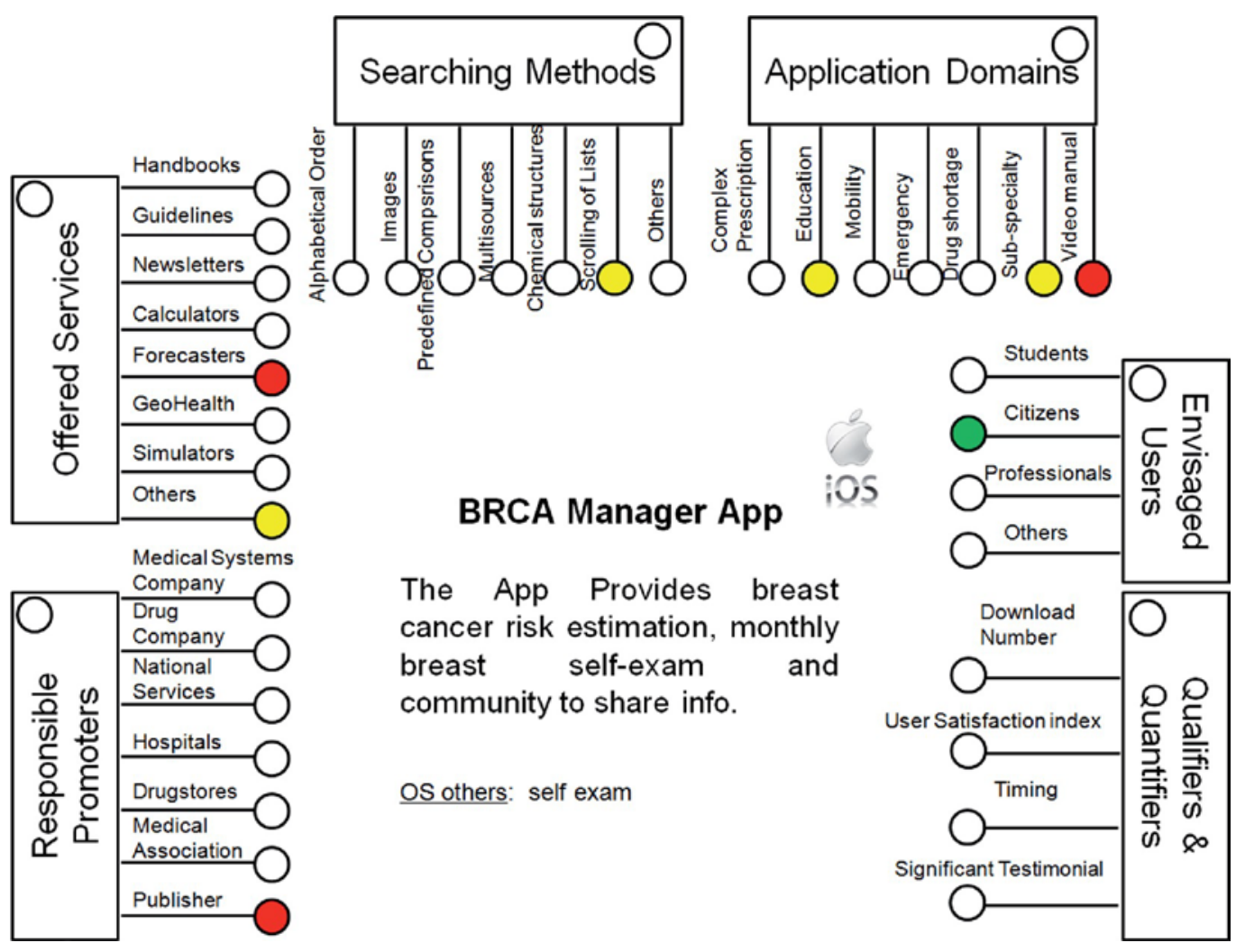


main, 24 for the oncology domain, and 40 for the pharma domain.

Figure 3 and Figure 4 show examples of single app one-shot identification pictorial schema for two Apps, one from the cardiology domain, and one for the oncology domain.

As reported in the center of Figure 3, the App "AF Guide" provides information/ answers for the management of drugs and behaviors in atrial fibrillation (AF). The responsible promoter is QxMD Software Inc, a company that produces certified medical devices. Since this promoter is trusted and active in the medical field, the corresponding lollipop is green. Whereas the guidelines provided are told to be referenced by "Evidence-based strategies", the App does not provide in-depth answers to questions regarding AF (attribute "Guidelines" in the "Offered services" yellow). Conversely, the risk calculator uses a too simplistic approach, as noted by the reviewersin iMedicalApps, thus making the calculator attribute in the "Offered Services" as well as the "Complex prescription" attributein the "Application Domains" red. Except the navigation tabs helping the user to navigate causes, clinical presentation, classification, symptoms, etc., information are mainly presented as lists, with a sub-optimal visualization effectiveness ("Scrolling of list" attribute yellow). In the "Application Domains" family, since the app addresses the AF "Specific sub-specialty" with some missing information (it does not provide in-depth answers to the questions regarding $\mathrm{AF}$ ) the scoring was set to yellow. For the same reason, the video-manuals to explain AF main characteristics that are available in the App are scored yellow. Even though not well declared in the App description, contents are well suited for students (green scoring) but incomplete for professionals (yellow scoring). Patients/ citizens are notincluded among Envisaged Users. We could not retrieve any satisfaction index/rating for this App, neither in iMedicalApps nor in the Apple Store, but we could find some users' comments. Among them, some were positive (students) and some were negative (professionals). For this reason, the scoring for this attribute was set to yellow.

Figure 4 shows the application of the pictorial schema to the BRCA Manager, an Appin the oncology domain for the breast

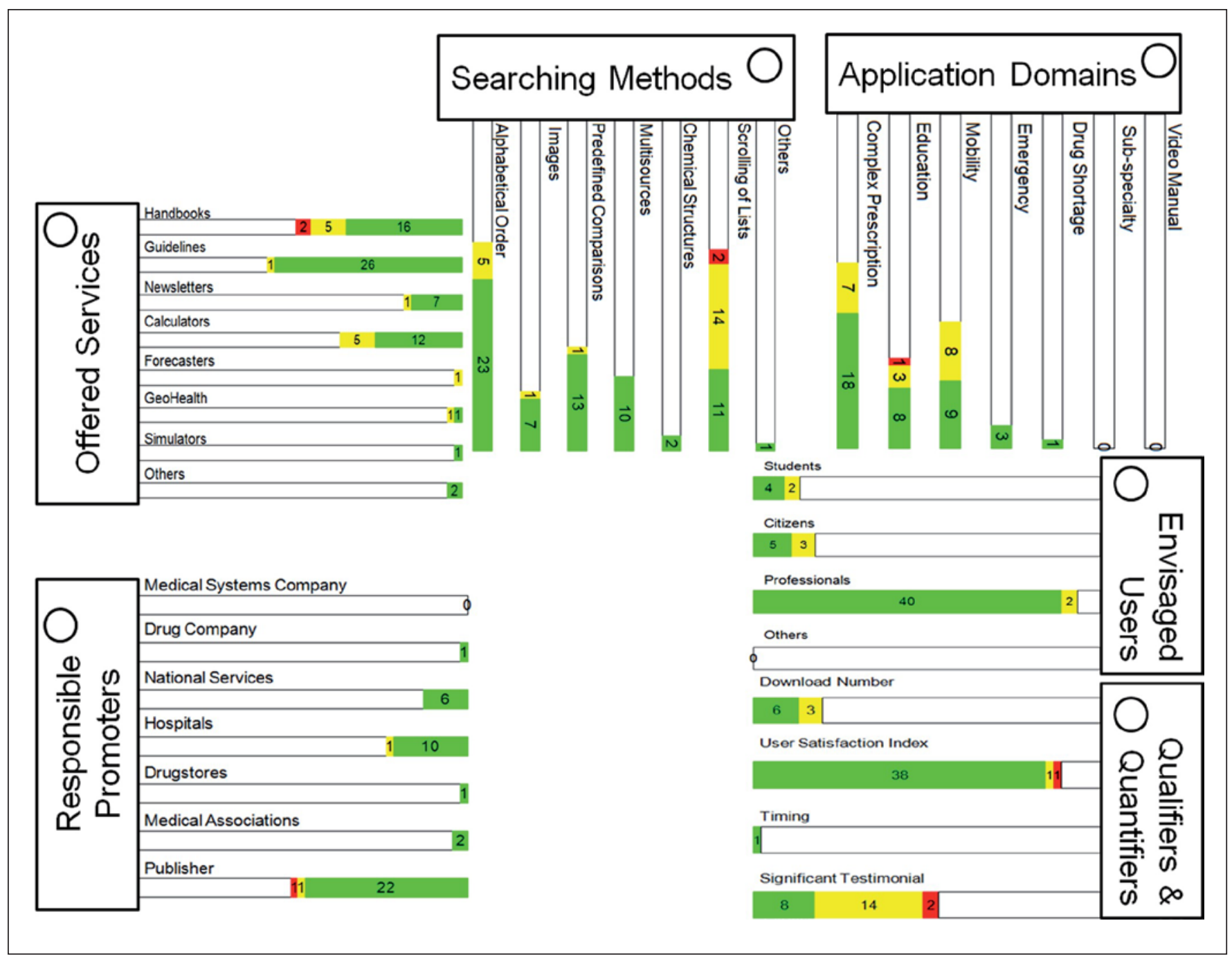

Figure 5 Aggregated results for the assessment of the Apps belonging to Pharma Domain 


\section{Figure 6}

Assessment of three Appsnotincludedin theApps selected to create the pictorial schema: A - the "Cardiology Flashcard Extra" app; Bthe "3DBrain"app

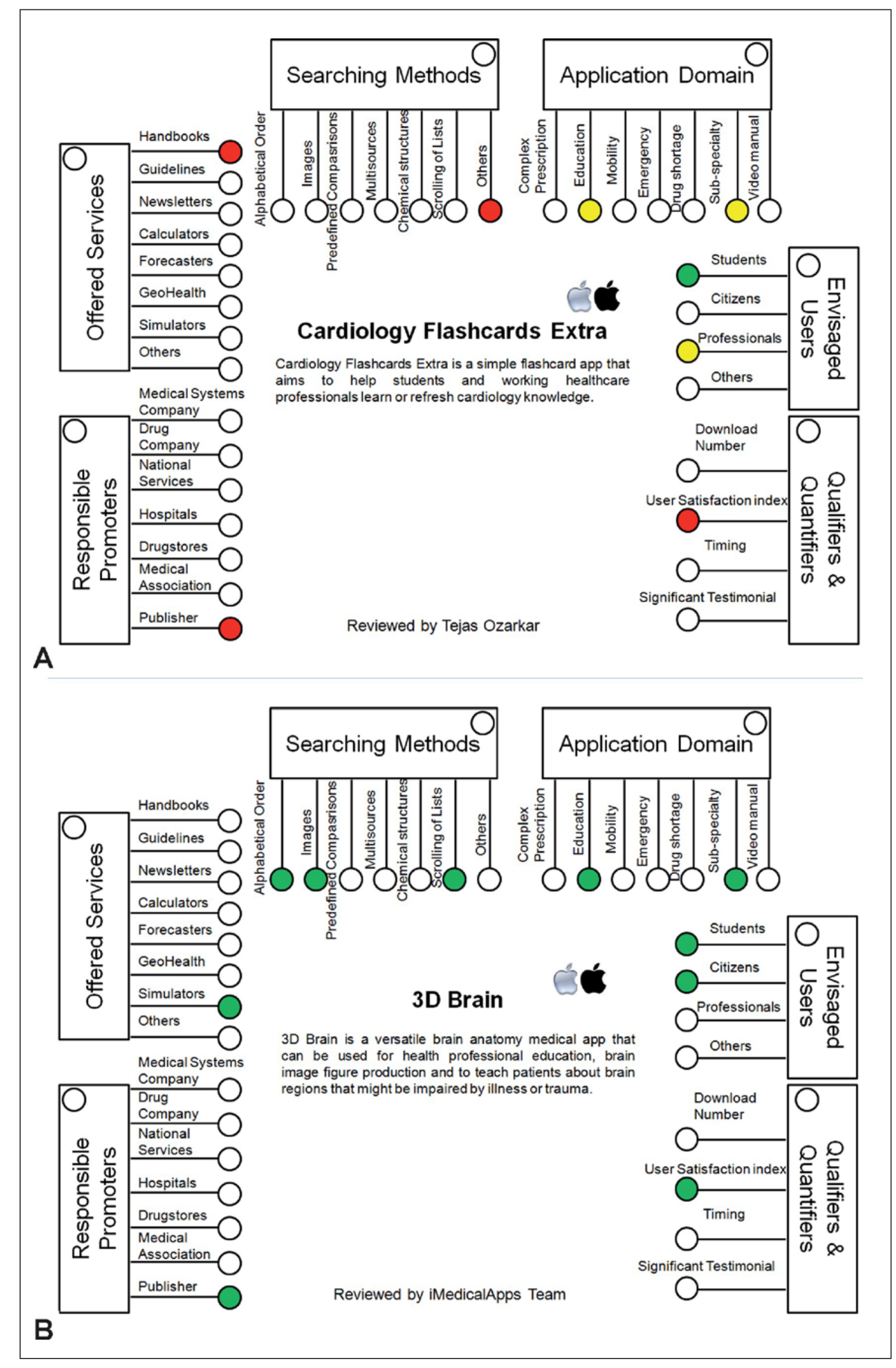




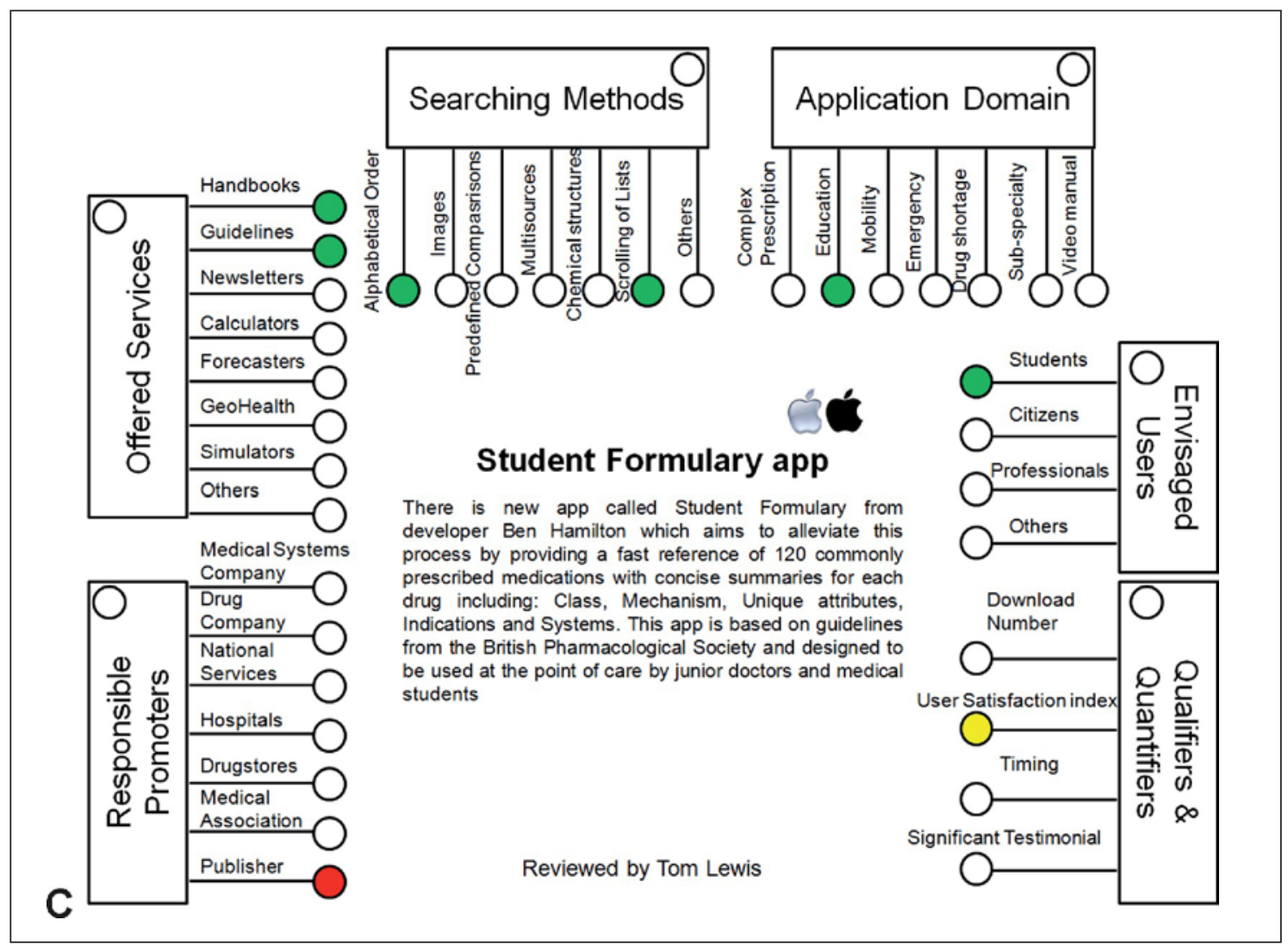

Figure 6

Assessment of three Appsnotincludedin the Apps selected to create the pictorial schema: C - the "StudentFormulary app" app

cancer risk assessment and advices for monthly breast exam. BRCA Manager was developed by Geference Inc, a medical publisher, that, to our knowledge and without other specific investigations, seems new and notyetranked in the medical domain ("publisher" attribute red). The provided risk calculator, that falls into the "Forecaster" category, is declared to be based on the model proposed by Gail etal. $[33,34]$ (BCRA tool developed by the National Cancer Institute) but there are two important drawbacks: first, the Gail model should be used by the patient together with a clinician, and, second, the model adopted is not complete. These drawbacks produced the red lollipop in the "Forecaster" attribute ("Offered Services"). Because the App offers also other services, including for instance a community to share experiences, the attribute "Others" was scored. The yellow color is due to the fact that the community service is not monitored by the developer. No specific "Searching Methods" are implemented in the App, except the list scrolling, which is however not highly effective (yellow "Scrol- ling of lists" attribute). For the lack of evidence based sources, and the superficial application of clinical models, the attributes in the "Application Domains" were scoredyellow or even red. Citizens (notyet patients, since it is aimed to prevention) are the declared "Envisaged Users" and the App is designed to meet their requirements.

We also tested whether our pictorial schema was able to show the quality of a group of Apps. The representative case of Pharma domain is represented in Figure 5 . Note that Figure 5 summarizes the results shown in Table 5 . In Figure 5 , the scores of all the Apps enrolled for the pharma domain were joined to obtain an overall domain perception.

\subsection{Application of the One-shot Pictorial Schemato the other Apps}

The application of the pictorial schema to other Apps did not reveal any inconsistency. For two of the three Apps, the schemas could be completely filled in by an independent user (biomedical engineer, $\mathrm{PhD}$ candidate) by using the available reviews. For the other App, the user faced the need to download and use the App. Figure 6 shows the three pictorial schemas for the chosen Apps.

\section{Discussion}

Our results show that it is possible to define a properly descriptive and structured pictorial schema, to be used as ID cardfor any medical app, independent from the specific medical domain. The schema provides a synthetic view on the strengths and on the risks related to a single App for different user's types. Attribute scores are provided in a common code (traffic-light code) to facilitate the perception on the App advantages/usefulness (green lights) as well as its caveats (red lights).

Our schema can be compiled or updated at any time window of the life of an App. Itcan be filled after its release, or after months. This is in line with the fast development rate that characterizes the mobile App arena, in which every day thousands 
of new Apps are released, and even more are updated or dismissed.

The "pictorial ID for Medical App" compiling can be carried outby a variety of user types, each of them forwarding the strength and weaknesses related to their role. A generically interested citizen, a healthcare provider, a doctor, a nurse, the app manufacturer, a declared cohort of users, a scientific society, a governmental body: all of these are examples of possible compilers. Each of them is widely interested in avoiding any risk, firstly for the patient, as well as for its own envisaged role. This implies that, for the same App, more than one identification schemas can be compiled, depending on the specific user, thus allowing a new user to understand when and where to use the App, with positive expectations. Since the scores given by the author of the pictorial schema strongly depend on their background, knowledge, and role, the "signature" of the author must accompany the one-shot pictorial schema.

Our results also showed that, in addition to providing a synthetic view on the single App, the pictorial schema is able to represent weaknesses and strengths of all the Apps in a single domain. These weaknesses and strengths can be due either to the uncertainty of the domain per se, or to a drawback still to be solved by mobile Applications.

\subsection{Limitations}

Our work was based on available medical professional reviews of Apps in three clinical domains (i.e., cardiology, oncology, and pharma). This choice allowed us to define a set of attributes that will be likely suited also to other clinical domains. However, the attribute set may be enriched by adding to the attributes we already identified other attributes coming from the personalized eHealth domain. For example, an App that provides a diary to befilled in by a diabetic patient, or by a patient suffering from migraine, is not well represented in the present attribute set. We may need to add the category of "enhancers", representing those tools that boost the communication between the patient and his/her physicians when the patient's condition requires frequent monitoring.
Also, we cannot exclude that, considering other types of App reviews, the pictorial schema should be improved. A step forward to our schema can be found in the recent FDA guidelines [16]. In fact, Apps that are not (or may be not) medical devices are listed in categories of services. These categories already include all the attributes of our "Offered Services" and "Searching Methods" families, but some others are defined thatcanbe used to enrich the schema.

\subsection{Dissemination Strategy}

One of the main drawbacks of the HON code project was the scares resonance it had on the general public. Whereas ehealth professionals know well the initiative, patients are poorly informed on it: less than $1 \%$ of people searching health information on the Internet use the HONcode seal to verify the medical information they retrieved [35]. This suggests that the dissemination strategy of any new attempt to identify/evaluate/represent Apps should impact the widest possible population. We made a first attempt to catch the professional public by presenting the pictorial schema at the National Congress of the the Italian College of Hopsital Cardiologists (Associazione Nazionale Medici Cardiologi Ospedalieri, ANMCO) that involves more than 5000 cardiologists in Italy [36]. The idea was well accepted by the public that recognized the need of such a useroriented approach. The next step in this direction will be the definition and administration of a questionnaire regarding the value of the families of attributes and of the attributes themselves that will be launched by our laboratory to all the main clinical, scientific, and patient associations in Italy, but also at the European level through the mediation of the European Federation of Medical Informatics (EFMI).

This action will contribute both to support the approach and to widen its diffusion among users. Other actions, likely in the direction of standardization bodies, should be planned to ensure wider diffusion not only to the manufacturers, but also to the governance and to those that run the big App market stores.

\section{Conclusion}

Despite the resulting schema is only a firststep towards an overall representation of strength and weaknesses of apps from the user's viewpoint, it appears reasonably transparent to be filled in and read. The usefulness and effectiveness of the "pictorial ID for Medical App" come both from its architecture and from the declared signature of its compiler. As a first step, the schema can be used as a "best practice" behavior adopted by the interested parties, for example by providing it together with the Appdescription on the marketstore. Then, the schema can be proposed to standardization bodies to become part of the recommendations or the rules regarding those medical Apps that are presently not covered by the FDA guidance. In addition, it has the potential for a wide dissemination, especially if promptly proposed to clinical and patients' scientific societies to obtain their contribution to the identification of appropriate attributes.

\section{Author Contribution}

All the authors contributed equally to the research and to the development of the one-shot pictorial schema, as well as to manuscript drafting and revision.

\section{References}

1. Marceglia S, Bonacina S, Zaccaria V,Pagliari C, Pinciroli F. How might the iPad change healthcare? J R Soc Med. 2012; 105 (6): 233-241.

2. Huckvale K, Car M, Morrison C, Car J. Apps for asthma self-management: a systematic assessment of contentand tools. BMCMed2012;10:144.

3. Ricciardi L, Mostashari F, Murphy J, Daniel JG, Siminerio EP. A national action plan to support consumer engagement via e-health. Health Aff (Millwood) 2013; 32 (2): 376-384.

4. Ozdalga E, Ozdalga A, Ahuja N. The smartphone in medicine: a review of current and potential use among physicians and students. J Med Internet Res 2012; 14 (5): e128.

5. Burki TK. Cancer apps. Lancet Oncol 2013; 14 (7): 580-581.

6. McCartney M. How do we know whether medical apps work? BMJ 2013; 346: f1811.

7. Most smartphone apps for melanoma detection are inaccurate. Health Devices 2013; 42 (4): 135.

8. Rosser BA, Eccleston C. Smartphone applications for pain management. J Telemed Telecare 2011; 17 (6): 308-312. 
9. Visvanathan A, Hamilton A, Brady RR. Smartphone apps in microbiology - is better regulation required? Clin Microbiol Infect 2012; 18 (7): E218-20.

10. Demidowich AP, Lu K, Tamler R, Bloomgarden Z. An evaluation of diabetes self-management applications for Android smartphones. J Telemed Telecare 2012; 18 (4):235-238.

11. Albrecht UV, von Jan U, Pramann O, Matthies HK. I, App: Trustworthy Medical Apps. T11 - Village of the Future - Pillar 5: Social and Policy Incentive Framework. Medical Informatics Europe - MIE 2012. August 26th-29th, 2012. Pisa, Italy. Available at URL: http://plrimedapplab.weebly.com/ publications.html. Accessed: November 15, 2013.

12. Lewis T. Apple now asking app developers to provide sources of medical information. (Online, September 18, 2013]). Available at URL: http://www. imedicalapps.com/2013/09/apple-app-developerssources-medical-information/ Accessed: November 15, 2013.

13. Huy NP, vanThanh D. Evaluation of mobile app paradigms. Proceeding of MoMM '12 - The 10th International Conference on Advances in Mobile Computing \& Multimedia. New York, NY; ACM; 2012. ISBN: 978-1-4503-1307-0, pp 25-30.

14. Peng H, Gates C, Sarma B, et al. Using probabilistic generative models for ranking risks of Android apps. Proceeding of CCS'12 - The 2012 Association Computing Machinery (ACM) conference on Computer and communications security. New York, NY; ACM; 2012. ISBN: 978-1-4503-1651-4, pp 241-252.

15. Barton AJ.The regulation of mobile health applications. BMC Med 2012; 10:46.

16. U.S. Department of Health and Human Services. Food and Drug Administration. Mobile Medical Applications - Guidance for Industry and Food and Drug Administration Staff. Available at URL: http://www.fda.gov/downloads/ MedicalDevices/DeviceRegulationandGuidance/ GuidanceDocuments/UCM263366.pdf Accessed: November 15, 2013.
17. Albrecht UV, Von Jan U, Pramann O. Standard reporting for medical apps. Stud Health Technol Inform 2013; 190: 201-203.

18. Albrecht UV, von Jan U, Jungnickel T, Pramann 0. App-synopsis - standard reporting for medical apps. Stud Health Technol Inform 2013; 192:1154.

19. Happtique. Health App Certification Program. Certification Standards. (Online, October 2013). Available at URL: http://www.happtique.com/ docs/HACP_Certification_Standards.pdf Accessed: November 15,2013.

20. Boyer C, Selby M, Scherrer JR, Appel RD. The Health On the Net Code of Conduct for medical and health Websites. Comput Biol Med 1998; 28 (5): 603-610.

21. Lewis TL. A systematic self-certification model for mobile medical apps. J MedInternet Res 2013; 15 (4): e89.

22. mHIMSS App Usability Work Group. Selecting a Mobile App: Evaluating the Usability of Medical Applications. The Healthcare Information and Management Systems Society (HIMSS). July 2012.

23. iMedicalApps. Available at URL: http://www. imedicalapps.com.Accessed:November 15,2013.

24. MedicalApp Journal. Available at URL: http:// medicalappjournal.com/ Accessed: November 15, 2013.

25. Dayer L, Heldenbrand S, Anderson P, Gubbins PO, Martin BC. Smartphone medication adherence apps: potential benefits to patients and providers.] Am Pharm Assoc 2013; 53 (2): 172-181.

26. Goldbach H, Chang AY, Kyer A, Ketshogileng D, TaylorL, Chandra A, Dacso M, Kung SJ, Rijken T, Fontelo P, Littman-Quinn R, Seymour AK, Kovarik CL. Evaluation of generic medical information accessed via mobile phones at the point of care in resource-limited settings. J Am Med Inform Assoc 2013 (Epub ahead of print). PubMed PMID: 23535665. Doi:10.1136/amiajnl-2012-001276.

27. WolfJA, Moreau JF, Akilov O, Patton T, English JC, Ho J, Ferris LK. Diagnostic inaccuracy of smartphone applications for melanoma detection. JAMADermatol 2013; 149(4): 422-426.
28. Franko OI. Smartphone apps for orthopaedic surgeons. Clin Orthop Relat Res 2011; 469 (7): 2042-2048.

29. Cornwall J,Pollard MF.Evaluation of free i-applications for tertiary level gross anatomy education. Australas Med J 2012; 5 (4): 239-242.

30. NHS Health Apps Library. Available at URL: http://apps.nhs.uk/ Accessed: November 15, 2013.

31. Marceglia S, Mazzola L, Bonacina S, Tarquini P, Donzelli P, Pinciroli F. A comprehensive e-prescribing model to allow representing, comparing, and analyzing available systems. Methods Inf Med 2013; 52 (3): 199-219.

32. International Organization for Standardization (ISO). IEC 62366:2007, Medical devices - Application of usability engineering to medical devices. 2008. Available at URL: http://www.iso.org/iso/ home/store/catalogue_ics/catalogue_detail_ics. htm?csnumber $=38594$ Accessed: November, 15 2013.

33. Gail MH, Brinton LA, Byar DP, Corle DK, Green SB, Shairer C, Mulvihill JJ: Projecting individualized probabilities of developing breast cancer for white females who are being examined annually. J NatlCancer Inst 1989;81(24): 1879-1886.

34. Rockhill B, Spiegelman D, Byrne C, Hunter DJ, Colditz GA. Validation of the Gail et al. model of breast cancer risk prediction and implications for chemoprevention. J Natl Cancer Inst 2001; 93 (5): 358-366.

35. Pletneva N, Vargas A, Boyer C. Health on the Net. Requirements for the general public health search. Deliverable of EU project KHRESMOI. (Online, May 20,2011). Available at URL:http://www.hon. ch/Global/pdf/Khresmoi/KHRESMOI_general_ public_survey_report.pdf. Accessed: November 15, 2013.

36. Associazione Nazionale Medici Cardiologi Ospedalieri (ANMCO). Available at URL: http:// www.anmco.it. Accessed: November 15, 2013 (in Italian). 